\title{
Tributo ao Professor Vietla Satyaranayana Rao
}

É muito difícil falar sobre um ser humano humilde, generoso e tão especial, feito o Prof. Rao!

A sua temporada no Brasil foi toda ela intimamente associada ao Programa de Pós-Graduação em Farmacologia da Universidade Federal do Ceará (UFC), Programa que teve início em 1978 e já contou com a participação do Prof. Rao, quatro anos depois (1982). Assim, o Prof. Rao acompanhou a evolução do Programa e dividiu conosco todos os problemas comuns a empreitadas como essa, tão importantes e fundamentais para toda Universidade no Brasil, especialmente para as Universidades Nordestinas. Lembro-me de que, nesse período, eu estava na Coordenação do Programa de Pós-graduação em Farmacologia da UFC e, como tal, batalhei junto às instituições em Brasília pela efetivação, em nosso programa, do Prof. Rao, então, Professor Visitante, posição que ocupou de 1982 até 1998. Em 1998, prestou concurso, sendo aprovado como Professor Adjunto, cargo que exerceu até 2005. À época, orientou vários estudantes de pós-graduação $(\mathrm{PG})$ do nosso programa, dentre esses, a Professora Flávia de Almeida Santos que concluiu o Doutorado em 1999. A Profa. Flávia prestou concurso para o Departamento de Fisiologia e Farmacologia da UFC, em 2004, tendo sido para o Professor Rao, desde então, uma importante colaboradora científica. Tal colaboração continuou, até mesmo após o regresso, em 2013, do Prof. Rao para a Índia, sua terra natal.

Em 2000, a Profa. Flávia e o Prof. Rao publicaram o artigo, Anti-inflammatory and Antinociceptive Effects of 1,8-Cineole, a Terpenoid Oxide Present in

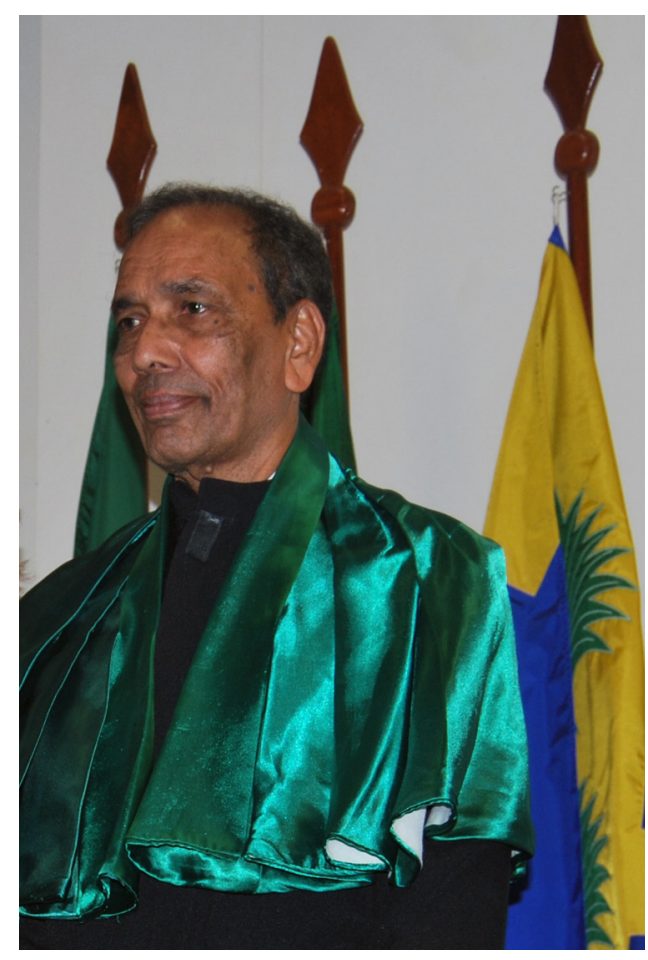
Many Plant Essential Oils, na importante revista científica Phytotherapy Research, obtendo o trabalho quase 600 citações. Outras espécies muito estudadas pelos Profs. Rao e Flávia foram: Protium heptaphyllum (Almecegueira, presente no Norte e Nordeste do Brasil) e Copaifera langsdorffii (Copaíba, comum na região Norte do Brasil), com centenas de citações.

O Prof. Rao voltou a prestar serviços à Universidade, de 2006 a 2010, como Professor Visitante. Em 2010, ao completar 70 anos, foi aposentado compulsoriamente, tendo então continuado na PG como Docente, junto ao PROPAP (Programa de Apoio aos Professores Aposentados da Universidade). O Prof. Rao também colaborou com o Programa de Pós-Graduação em Ciências Médicas da UFC, havendo participado do Colegiado deste curso, de 2006-2012. Ademais, foi Pesquisador 1B do CNPq, até março de 2013. O Professor Rao sempre trabalhou com plantas medicinais brasileiras e, apesar do foco recair sobre o estudo farmacológico dessas plantas, interagia fortemente com os pesquisadores do setor de Química Orgânica da UFC, estabelecendo parcerias e colaborações das mais produtivas. Como resultado, vários estudantes de PG, tanto em Farmacologia quanto em Química Orgânica, foram formados direta ou indiretamente sob sua orientação, sendo atualmente incorporados à Docência Universitária, pelo Brasil afora. Deste modo, orientou várias gerações de pesquisadores farmacologistas que se vincularam à UFC ou a outras instituições de ensino e pesquisa no Brasil e no exterior. Participava ativamente, com seus estudantes, de simpósios especializados, como é o caso do Simpósio de Plantas Medicinais do Brasil, com contribuições importantes para o conhecimento de propriedades farmacológicas de plantas medicinais.

O Prof. Henry de Holanda Campos, Vice-Reitor no exercício da Reitoria, ao saudar, na noite de 26 de fevereiro de 2014, o Prof. Vietla Satyranayana Rao, a quem era outorgado o título de Professor Emérito, afirmou ser o homenageado "uma das personalidades acadêmicas, abrigadas sob o teto da Universidade Federal do Ceará, que se dedicam a erigir um mundo novo, investindo nessa tarefa, em grandes doses, a força de sua inteligência".

Como escolhida que fui, com muita honra, para apresentar e saudar o homenageado, durante aquela solene cerimônia, enfatizei que o Prof. Rao, ao longo de sua profícua vida acadêmica, construiu todo um acervo científico, focado, principalmente, no estudo da planta medicinal e de seus constituintes bioativos, tornando-se referência nacional e internacional sobre o tema. Destaquei também em meu pronunciamento, que na convivência de quase três décadas com o Prof. Vietla Rao, no Departamento de Fisiologia e Farmacologia, chegava ele ao trabalho, por volta das $7 \mathrm{~h}$ da manhã, sendo sempre um dos colegas mais assíduos e envolvidos com as lides da Docência e da Pesquisa.

Retornando à sua terra natal, em 2013, o Prof. Rao deixou saudades e um grande vazio que não será facilmente preenchido. Neste ano de 2021, mais precisamente no dia 30 de abril, partiu definitivamente para a outra dimensão e, assim, a Farmacologia de 
Produtos Naturais do Brasil, em especial do Ceará, perde um de seus maiores pesquisadores e formadores de recursos humanos qualificados, e agora multiplicadores de seus ensinamentos, por todo o país.

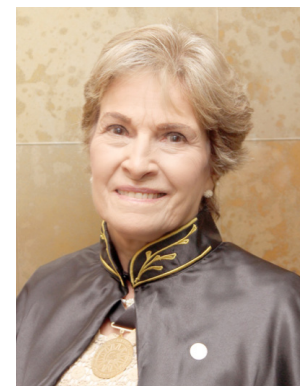

Dra. Glauce Socorro de Barros Viana Departamento de Fisiologia e Farmacologia Universidade Federal do Ceará

Como citar:

Viana GS. Tributo ao Professor Vietla Satyaranayana Rao. Rev Med UFC. 2021;61(1):1-2. 